\title{
Plant Growth Regulator Effects on In Vitro Propagation and Stevioside Production in Stevia rebaudiana Bertoni
}

\author{
Bärbel Röck-Okuyucu \\ School of Tobacco Expertise, Celal Bayar University, Akhisar/Manisa, \\ Turkey
}

Meltem Bayraktar ${ }^{1}$

Biotechnology Department, Graduate School of Nature and Applied Sciences, Ege University, Bornova/Izmir 35100, Turkey; and Genetic and Bioengineering Department, Faculty of Engineering and Architecture, Ahi Evran University, Kirsehir 40100, Turkey

Ismail Hakki Akgun and Aynur Gurel

Bioengineering Department, Faculty of Engineering, Ege University, Bornova/Izmir 35100, Turkey

Additional index words. dulcoside A, HPLC, in vitro, rubusoside, steviolbioside, stevioside

Abstract. Stevia rebaudiana is of great importance due to its steviol glycosides (SGs) which are natural sweeteners used by the food industry as well as having medicinal purposes. In the present study, the effect of plant growth regulators (PGRs) and explant types on in vitro propagation and shoot growth of $S$. rebaudiana were studied, the effect of PGRs on SGs production was determined. For this purpose, nodal explants and shoot tip explants were cultured on woody plant medium (WPM) supplemented with cytokinins [6-benzyladenine (BA), kinetin (Kn), or thidiazuron (TDZ)] or cytokinins + auxins combinations [BA + indoleacetic acid (IAA); BA + naphthaleneacetic acid (NAA); Kn + IAA; Kn + NAA] Although, the best shoot proliferation was obtained on WPM supplemented with BA + NAA combinations, shoots grown on PGR-containing media produced callus at the base of the shoots and showed chlorosis and necrosis. Additionally, shoots showed at all concentrations of TDZ, and at higher concentrations of BA, morphological changes such as malformed leaves and poor shoot growth. In contrast to PGR-containing media, on the PGR-free control medium, the development of shoots and roots occurred simultaneously and healthy and well-developed plantlets were obtained. Thus, we developed an economical viable means of in vitro propagation by minimizing the micropropagation steps and removing the requirement of PGRs. According to the high-performance liquid chromatography (HPLC) results, PGR-free control medium (WPM) led to considerably higher stevioside content in the leaves compared with the PGR(s)-containing media and the highest stevioside [34 mg. $\mathrm{g}^{-1}$ dry weight (DW)] and rebaudioside A content was only detected on the control medium without PGRs. Steviolbioside, rubusoside, and dulcoside A were detected qualitatively in the leaves of shoots grown on WPM supplemented with $2.27 \mu \mathrm{M}$ TDZ, 4.54 $\mu_{M}$ TDZ, $2.22 \mu M$ BA + 2.69 $\mu$ NAA, $2.22 \mu M$ BA + 5.37 $\mu_{M}$ NAA, $2.32 \mu M ~ K n+$ $5.71 \mu_{M}$ IAA, or $2.32 \mu_{M} \mathrm{Kn}+2.69 \mu_{M}$ NAA.

Stevia rebaudiana Bertoni belongs to the family Asteraceae and is a perennial that is primarily native to eastern Paraguay (Brandle et al., 1998). S. rebaudiana accumulates mainly in its leaves $\approx 34$ noncaloric sweettasting SGs (Ceunen and Geuns, 2013). The two main SGs produced in the leaves are

\footnotetext{
Received for publication 27 June 2016. Accepted for publication 15 Sept. 2016

This research was supported by Celal Bayar University Scientific Research Projects Commission (ALS 2008-069).

We are so grateful to Erdal Bedir and Norm Kimya San.Tic.Ltd.Şti.

${ }^{1}$ Corresponding author. E-mail: meltembayraktar5@ gmail.com
}

stevioside and rebaudioside A (Kinghorn, 2002). The sweetening properties of Stevia leaves have already been used since the sixteenth century by the native Paraguayan populations in the Amambay region (Soejarto, 2002). In the early 1970s, Japan started the commercial cultivation of $S$. rebaudiana, and sometime later the first Stevia products have been offered on the Japanese market. Since then, Stevia has been introduced in several countries and can be used as food additive and for therapeutic purposes (Brandle et al., 1998; Lemus-Mondaca et al., 2012).

In general, Stevia plants are propagated by seeds or vegetative cuttings. Since the Stevia seeds are very small and infertile, they have poor germination rate. Therefore, large-scale production of Stevia via seeds is not efficient (Brandle et al., 1998; Gantait et al., 2015). Besides this, the seeds show a wide variation with regard to the SGs content as well as the morphological features (the shape and color of leaves) (Tamura et al., 1984). Clonal propagation via vegetative cuttings is practical for small-scale production, but it is not suitable due to the small number of individuals and economically viable because of high labor costs for large-scale production (Brandle et al., 1998; Gantait et al., 2015). A genetically homogeneous population, which produces high yields of the desired SGs, can be achieved by in vitro propagation of a selected plant (Gantait et al., 2015; Lemus-Mondaca et al., 2012; Tamura et al., 1984). The use of apical and axillary meristems, shoot tips, or nodal explants for in vitro production, enables the conservation of the genotype during clonal propagation. In addition, in vitro plant propagation using axillary buds was reported to be a simple and economic method to obtain many genetically uniform true-to-type plants within a short period (Faisal et al., 2007).

The presence of diterpene glycosides was investigated in callus culture, suspension culture (Bondarev et al., 2001; Mathur and Shekhawat, 2013), etiolated in vitro regenerants, callus culture grown in the light, etiolated heterotrophic callus (Ladygin et al., 2008), hairy root culture (Pandey et al., 2016; Yamazaki and Flores, 1991), in vitro root culture (Reis et al., 2011), in leaf-derived callus cultures (Sivaram and Mukundan, 2003 ), salts $\left(\mathrm{NaCl}\right.$ and $\left.\mathrm{Na}_{2} \mathrm{CO}_{3}\right)$, proline or polyethylene glycol-treated callus, and suspension culture (Gupta et al., 2014, 2015). However, there is little information about the effect of PGRs on SGs of in vitro-propagated Stevia shoots. The synthesis of SGs is initiated in the chloroplasts and takes place mainly in the leaves (Brandle and Telmer, 2007; Ladygin et al., 2008). The SGs production varies from clone to clone as well as depending on the physical conditions under which Stevia plants are regenerated. It is of particular interest to develop new $S$. rebaudiana varieties with a high SGs content and to obtain sufficient propagating and planting material which possesses this quality characteristic. The extracts with homogeneous and high secondary metabolite contents can be achieved in vitro under controlled physical conditions, using a suitable growth media. Furthermore, it is possible to achieve within a considerably short time a large number of, with regard to development and growth, uniform Stevia plantlets by in vitro propagation. Therefore, the purpose of the present study was to develop an efficient and economical in vitro propagation protocol for a selected clone line of $S$. rebaudiana. Furthermore, to determine the effect of some PGRs on the shoot growth and SGs production.

\section{Materials and Methods}

\section{Stevia rebaudiana shoot cultures}

In vitro clonally propagated plantlets, which were obtained from single seed descent seedlings of $S$. rebaudiana, were used as the 
plant material. To obtain a sufficient number of plants, nodal segments and shoot tips (with one axillary bud) of 4-week-old plantlets were transferred to glass tubes each containing $10 \mathrm{~mL}$ of WPM (Lloyd and McCown, 1980) supplemented with $3 \%(\mathrm{w} / \mathrm{v})$ sucrose, and solidified with $0.65 \%(\mathrm{w} / \mathrm{v})$ plant agar (Duchefa Biochemie B.V., Haarlem, The Netherlands). The $\mathrm{pH}$ of all media was adjusted to 5.8 before the addition of the gelling agent, and they were autoclaved at $121{ }^{\circ} \mathrm{C}$ at $1.04 \mathrm{~kg} \cdot \mathrm{cm}^{-2}$ for $15 \mathrm{~min}$. For plant multiplication, they were transferred every 4 weeks to fresh solidified medium.

\section{PGR application and culture conditions}

To investigate the effect of different PGRs on shoot proliferation and growth as well as on SGs production, two different explant types as specified above, were used. The explants were cultured in glass tubes each containing $10 \mathrm{~mL}$ of WPM supplemented with various concentrations of different PGRs, $3 \%(\mathrm{w} / \mathrm{v})$ sucrose, and $0.65 \%$ $(\mathrm{w} / \mathrm{v})$ agar (Table 1).

The cultures were incubated in a growth room under $26 \pm 1{ }^{\circ} \mathrm{C}$ in a cool white fluorescent light $\left(50 \mu \mathrm{mol} \cdot \mathrm{m}^{-2} \cdot \mathrm{s}^{-1}\right)$ and a $16-\mathrm{h}$ photoperiod for 4 weeks.

\section{Acclimatization}

Acclimatization of the in vitro-rooted plantlets was carried out in a climate chamber under $25 \pm 1{ }^{\circ} \mathrm{C}, 70 \%$ humidity, $50 \mu \mathrm{mol} \cdot \mathrm{m}^{-2} \cdot \mathrm{s}^{-1}$ irradiance, and $16-\mathrm{h}$ photoperiod conditions. Plantlets, $8-10 \mathrm{~cm}$ long with 10-14 leaves and well-developed roots, were carefully removed from the culture vessels, and their roots were washed with water. Each plantlet was transferred to a $5-\mathrm{cm}$ diameter pot containing a 1:3 peat:loam mixture and was completely covered with perforated transparent bags to retain humidity. These plants were ventilated for
10 min by removing the bags from the plants once a day for a period of 2 weeks. The acclimation bags were completely removed at the end of the 2-week period. The plants were then transferred from the climate chamber to the greenhouse conditions 3 weeks after the beginning of acclimatization and were maintained there for a period of 5 weeks. Completely acclimatized plants were transferred to field conditions at the end of 8 weeks.

\section{SGs analysis}

Chemicals. HPLC grade acetonitrile and methanol were purchased from Merck (Darmstadt, Germany). The ultrapure water, used for the analysis, was obtained from an in-house ultrapure water system (Sartorius Arium 611; Sartorius Stedim Biotech, Göttingen, Germany). Stevioside and rebaudioside A were isolated from the leaves of $S$. rebaudiana by our research group with a purity of $+90 \%$.

HPLC sample preparation. Appoximately $75 \mathrm{mg}$ of leaf samples were sonicated three times with $5 \mathrm{~mL}$ methanol for $20 \mathrm{~min}$. The clear extracts were combined and diluted with methanol to $20 \mathrm{~mL}$. Before HPLC analysis, the samples were filtered with a $0.45-\mu \mathrm{m}$ polytetrafluoroethylene filter (Sartorius AG, Göttingen, Germany) to remove nondissolved particles.

HPLC-evaporative light-scattering detector conditions. HPLC-evaporative light-scattering detector (ELSD) analyses were performed with a Thermo Surveyor Plus HPLC (Thermo Fisher Scientific, Waltham, MA) equipped with a quaternary pump, an autosampler, and a SofTA 300S ELS Detector (SofTA Corporation, Westminster, CO). As the analytical column, an apHera $\mathrm{NH}_{2}$ column $(150 \mathrm{~mm} \times 4.6 \mathrm{~mm}$, particle size $5 \mu \mathrm{m}$, Sigma Aldrich, Germany) was used. An acetonitrile/water mixture $(75: 25 \mathrm{v} / \mathrm{v})$ served as isocratic mobile phase. The total run time was $10 \mathrm{~min}$ at a flow rate of
$0.8 \mathrm{~mL} \cdot \mathrm{min}^{-1}$. A sample of $10 \mu \mathrm{L}$ was injected (partial loop injection) each run. The spray chamber temperature was set to $40{ }^{\circ} \mathrm{C}$, the drift tube temperature to $105{ }^{\circ} \mathrm{C}$, the gas pressure to $50 \mathrm{psi}$, and the filter of the ELSD to 6 . The retention time was $4.22 \mathrm{~min}$ for stevioside and 6.12 min for rebaudioside A.

Liquid chromatography-mass spectrometry analysis. Liquid chromatography-mass spectrometry (LC-MS) experiments for the qualitative identification of steviol derivatives were performed on a Thermo Accela UPLC instrument, equipped with a TSQ Quantum Access MAX Triple Quadrople Mass Spectrometer (Thermo Scientific, Bremen, Germany). Thermo Accela UPLC system consists of a high-pressure quaternary pump, an autosampler, and a column oven. Separations were carried out by in-house generated method with the following conditions. For all separations, a Teknokroma RP C18 $250 \mathrm{~mm} \times 4.6 \mathrm{~mm} \times$ $5 \mu \mathrm{m}$ column (Teknochroma, Barcelona, Spain) was used. LC separations were carried out using following solvents: ultrapure water (A) and acetonitrile (B) and gradient elution was performed as: $0-1 \min 65 \mathrm{~A} / 35 \mathrm{~B}$, in $4 \mathrm{~min}$ to $63 \mathrm{~A} / 27 \mathrm{~B}$, in $2.5 \mathrm{~min}$ to $60 \mathrm{~A} / 40 \mathrm{~B}$, in $0.5 \mathrm{~min}$ to $5 \mathrm{~A} / 95 \mathrm{~B}$, and kept at that composition for 3 min and changed to initial ratios $(65 \mathrm{~A} / 35 \mathrm{~B})$ of method in $1 \mathrm{~min}$. Before the next injection, the column was equilibrated for $3 \mathrm{~min}$ with the beginning conditions $(65 \mathrm{~A} / 35 \mathrm{~B})$. Flow rate was $1 \mathrm{~mL} \cdot \mathrm{min}^{-1}$ and column temperature was $40^{\circ} \mathrm{C}$. LC-MS experiments were performed in electrospray ionization (ESI) $(+)$ mode with capillary temperature set to $320^{\circ} \mathrm{C}$, vaporizer temperature set to $350{ }^{\circ} \mathrm{C}$, and spray voltage set to $3000 \mathrm{~V}$. Pressures of sheath and aux gas of probe were set to 50 and 25 psi, respectively. All the samples were scanned between 600 and $1200 \mathrm{amu}$ to qualitatively identify Stevia glycosides. Existence of Stevia glycosides were examined by scanning their molecular

Table 1. Effects of different types and concentrations of PGRs and explant types on the shoot proliferation in Stevia rebaudiana.

\begin{tabular}{|c|c|c|c|c|c|c|c|c|c|c|}
\hline \multicolumn{5}{|c|}{ Concentrations of PGRs $(\mu \mathrm{M})$} & \multicolumn{2}{|c|}{ Mean number of shoots/explant $\pm \mathrm{SE}$} & \multicolumn{2}{|c|}{ Mean shoot lengths $(\mathrm{cm}) /$ explant $\pm \mathrm{SE}$} & \multicolumn{2}{|c|}{ Mean number of nodes/explant $\pm \mathrm{SE}$} \\
\hline$\overline{\mathrm{BA}}$ & $\mathrm{Kn}$ & TDZ & IAA & NAA & Nodal explant & Shoot tip explant & Nodal explant & Shoot tip explant & Nodal explant & Shoot tip explant \\
\hline$\overline{-}$ & - & - & - & - & $2.00 \pm 0.00 \mathrm{e}$ & $1.20 \pm 0.03 \mathrm{~h}$ & $7.88 \pm 0.06 \mathrm{~d}$ & $12.44 \pm 0.02 \mathrm{ab}$ & $7.87 \pm 0.05 \mathrm{de}$ & $6.73 \pm 0.09 \mathrm{gh}$ \\
\hline 2.22 & - & - & - & - & $7.60 \pm 0.10 \mathrm{ab}$ & $7.51 \pm 0.06 \mathrm{~b}$ & $2.89 \pm 0.06 \mathrm{fg}$ & $3.27 \pm 0.05 \mathrm{fgh}$ & $5.68 \pm 0.03 \mathrm{fg}$ & $6.64 \pm 0.08 \mathrm{gh}$ \\
\hline 4.44 & - & - & - & - & $6.51 \pm 0.08 \mathrm{bc}$ & $6.00 \pm 0.06 \mathrm{c}$ & $3.57 \pm 0.00 \mathrm{f}$ & $4.03 \pm 0.04 \mathrm{efg}$ & $5.82 \pm 0.09 \mathrm{fg}$ & $6.00 \pm 0.16 \mathrm{~h}$ \\
\hline 8.88 & - & - & - & - & $4.98 \pm 0.13 \mathrm{~d}$ & $6.04 \pm 0.06 \mathrm{c}$ & $2.28 \pm 0.03 \mathrm{fgh}$ & $2.23 \pm 0.07 \mathrm{hi}$ & $2.95 \pm 0.03 \mathrm{ij}$ & $3.70 \pm 0.09 \mathrm{ij}$ \\
\hline 17.76 & - & - & - & - & $4.49 \pm 0.08 \mathrm{~d}$ & $5.40 \pm 0.16 \mathrm{c}$ & $1.61 \pm 0.04 \mathrm{gh}$ & $1.67 \pm 0.05 \mathrm{i}$ & $2.84 \pm 0.11 \mathrm{ij}$ & $3.15 \pm 0.12 \mathrm{ijk}$ \\
\hline - & 2.32 & - & - & - & $2.27 \pm 0.03 \mathrm{e}$ & $3.29 \pm 0.11 \mathrm{de}$ & $9.62 \pm 0.10 \mathrm{c}$ & $11.24 \pm 0.02 b$ & $6.56 \pm 0.13 \mathrm{ef}$ & $8.62 \pm 0.10 \mathrm{def}$ \\
\hline - & 4.65 & - & - & - & $2.22 \pm 0.06 \mathrm{e}$ & $2.82 \pm 0.04$ ef & $7.90 \pm 0.04 \mathrm{~d}$ & $12.64 \pm 0.03 \mathrm{a}$ & $3.91 \pm 0.03 \mathrm{hi}$ & $4.31 \pm 0.06 \mathrm{i}$ \\
\hline - & 9.29 & - & - & - & $1.91 \pm 0.01 \mathrm{e}$ & $2.24 \pm 0.04 \mathrm{efgh}$ & $11.36 \pm 0.11 b$ & $11.30 \pm 0.18 b$ & $7.02 \pm 0.01 \mathrm{ef}$ & $8.04 \pm 0.15 \mathrm{defg}$ \\
\hline - & 18.59 & - & - & - & $1.91 \pm 0.01 \mathrm{e}$ & $1.20 \pm 0.02 \mathrm{~h}$ & $7.22 \pm 0.06 \mathrm{~d}$ & $6.43 \pm 0.07 \mathrm{~d}$ & $4.64 \pm 0.03 \mathrm{gh}$ & $6.80 \pm 0.21 \mathrm{gh}$ \\
\hline - & - & 2.27 & - & - & $2.69 \pm 0.05 \mathrm{e}$ & $2.44 \pm 0.12 \mathrm{efg}$ & $3.19 \pm 0.12 \mathrm{f}$ & $3.06 \pm 0.06 \mathrm{gh}$ & $4.00 \pm 0.13 \mathrm{hi}$ & $4.21 \pm 0.04 \mathrm{i}$ \\
\hline - & - & 4.54 & - & - & $2.30 \pm 0.03 \mathrm{e}$ & $2.64 \pm 0.01 \mathrm{ef}$ & $2.78 \pm 0.04 \mathrm{fg}$ & $2.46 \pm 0.03 \mathrm{hi}$ & $2.76 \pm 0.04 \mathrm{ij}$ & $3.10 \pm 0.06 \mathrm{ijk}$ \\
\hline - & - & 9.08 & - & - & $1.98 \pm 0.01 \mathrm{e}$ & $1.98 \pm 0.04 \mathrm{fgh}$ & $1.87 \pm 0.04 \mathrm{gh}$ & $2.45 \pm 0.05 \mathrm{hi}$ & $2.15 \pm 0.04 \mathrm{j}$ & $2.35 \pm 0.09 \mathrm{jk}$ \\
\hline - & - & 18.16 & - & - & $2.00 \pm 0.01 \mathrm{e}$ & $2.09 \pm 0.09 \mathrm{fgh}$ & $1.38 \pm 0.04 \mathrm{~h}$ & $1.99 \pm 0.06 \mathrm{hi}$ & $2.50 \pm 0.10 \mathrm{ij}$ & $2.05 \pm 0.13 \mathrm{k}$ \\
\hline 2.22 & - & - & 2.85 & - & $6.27 \pm 0.03 \mathrm{c}$ & $6.16 \pm 0.01 \mathrm{c}$ & $5.38 \pm 0.03 \mathrm{e}$ & $4.47 \pm 0.06$ ef & $6.49 \pm 0.08 \mathrm{ef}$ & $7.24 \pm 0.09 \mathrm{fgh}$ \\
\hline 2.22 & - & - & 5.71 & - & $2.62 \pm 0.04 \mathrm{e}$ & $3.93 \pm 0.06 \mathrm{~d}$ & $8.42 \pm 0.13 \mathrm{~cd}$ & $6.60 \pm 0.10 \mathrm{~cd}$ & $6.29 \pm 0.05$ ef & $7.47 \pm 0.14$ efgh \\
\hline 2.22 & - & - & - & 2.69 & $6.29 \pm 0.03 \mathrm{c}$ & $10.02 \pm 0.13 \mathrm{a}$ & $5.24 \pm 0.06 \mathrm{e}$ & $4.57 \pm 0.06$ ef & $10.07 \pm 0.21 \mathrm{c}$ & $14.40 \pm 0.04 \mathrm{~b}$ \\
\hline 2.22 & - & - & - & 5.37 & $8.00 \pm 0.09 \mathrm{a}$ & $9.33 \pm 0.09 \mathrm{a}$ & $5.13 \pm 0.11 \mathrm{e}$ & $5.09 \pm 0.09 \mathrm{e}$ & $14.44 \pm 0.19 \mathrm{a}$ & $16.16 \pm 0.15 \mathrm{a}$ \\
\hline - & 2.32 & - & 2.85 & - & $7.51 \pm 0.10 \mathrm{ab}$ & $6.42 \pm 0.07 \mathrm{bc}$ & $5.17 \pm 0.12 \mathrm{e}$ & $7.17 \pm 0.20 \mathrm{~cd}$ & $11.91 \pm 0.18 b$ & $11.73 \pm 0.06 \mathrm{c}$ \\
\hline - & 2.32 & - & 5.71 & - & $4.69 \pm 0.03 \mathrm{~d}$ & $4.09 \pm 0.12 \mathrm{~d}$ & $7.36 \pm 0.24 \mathrm{~d}$ & $7.86 \pm 0.30 \mathrm{c}$ & $9.49 \pm 0.27 \mathrm{~cd}$ & $9.16 \pm 0.07 \mathrm{~d}$ \\
\hline - & 2.32 & - & - & 2.69 & $2.16 \pm 0.05 \mathrm{e}$ & $1.82 \pm 0.03 \mathrm{fgh}$ & $12.70 \pm 0.05 \mathrm{a}$ & $13.16 \pm 0.02 \mathrm{a}$ & $9.93 \pm 0.05 \mathrm{c}$ & $9.02 \pm 0.16 \mathrm{de}$ \\
\hline - & 2.32 & - & - & 5.37 & $1.89 \pm 0.02 \mathrm{e}$ & $1.44 \pm 0.06 \mathrm{gh}$ & $12.54 \pm 0.19 \mathrm{ab}$ & $13.07 \pm 0.03 \mathrm{a}$ & $10.42 \pm 0.11 b c$ & $7.80 \pm 0.21 \mathrm{defg}$ \\
\hline
\end{tabular}

$\mathrm{BA}=$ 6-benzyladenine; IAA = indoleacetic acid; $\mathrm{Kn}=$ kinetin; NAA = naphthaleneacetic acid; PGR = plant growth regulator; TDZ = thidiazuron.

Values represent mean \pm SE of three replications, with 15 explants per replicate. Values (mean $\pm \mathrm{SE}$ ) sharing the same letter in the same column is not significantly different at $P \leq 0.01$, according to least significant difference test. Data were recorded after 4 weeks of culture. 
mass and their typical ESI adducts $\left[\mathrm{M}+\mathrm{NH}_{4}\right]^{+}$ $\left([\mathrm{M}+18]^{+}\right.$signals) (Keller et al., 2008).

\section{Statistical analysis}

The data were recorded 4 weeks after culture initiation. The experiments were set up in a completely randomized design, and the experiments were conducted in three replications with 15 explants in each replication. Forty-five explants were tested in total per treatment. Data were analyzed using the Tarist software package (Acikgoz et al., 2004). Differences between the means were tested using the least significant difference test at the 0.01 level of significance.

\section{Results}

Effect of different explant types and PGRs on shoot proliferation and in vitro plant growth. To determine a suitable medium for an efficient in vitro propagation of $S$. rebaudiana, explants were cultured on WPM supplemented with different PGRs. WPM supplemented with BA in combination with NAA gave the best response regarding shoot proliferation. The highest number of shoots (10.02 shoots/shoot tip explant) was achieved in cultures established on WPM supplemented with $2.22 \mu \mathrm{M}$ BA + $2.69 \mu \mathrm{M}$ NAA (Table 1). Of the three cytokinins (BA, Kn, and TDZ), BA was more effective than $\mathrm{Kn}$ and TDZ in both nodal and shoot tip explants in terms of shoot proliferation. Retrogression and abnormalities were observed in shoots grown on WPM with the two highest concentrations of BA as well as in all plantlets grown on TDZ-containing medium. Thin, short shoots with short internodes and formless leaves, which made them unsuitable for in vitro propagation were found in both nodal and shoot tip explants (Fig. 1B and D).

A considerable variation existed among the tested cytokinins with regard to the mean shoot length, which ranged between $1.38 \mathrm{~cm}$ (nodal explants grown on WPM with $18.16 \mu \mathrm{M}$ TDZ) and $13.16 \mathrm{~cm}$ (shoot tip explants grown on WPM with $2.32 \mu \mathrm{M} \mathrm{Kn}+2.69 \mu \mathrm{M}$ NAA). Although Kn inhibited multiple shoot regeneration and led to a reduced number of shoots per explant, Kn had a positive effect on the shoot length (Table 1). Furthermore, shoots grown on WPM supplemented with $\mathrm{Kn}$ showed a larger leaf area than those grown on BA- or TDZ-containing medium (Fig. 1C).

The mean number of nodes per explant was ascertained, as the number of nodes is a significant indicator for the proliferation rate, when nodal explants are used for in vitro propagation. The maximum number of nodes per explant (16.16 nodes/shoot tip explant) was obtained on WPM supplemented with $2.22 \mu \mathrm{M} \mathrm{BA}+5.37 \mu \mathrm{M}$ NAA (Table 1).

In all medium combinations and in both nodal and shoot tip explants, in which multiple shoot formation was observed, the young shoots were formed from the first, second, third, fourth, and fifth nodes of the main shoot (Fig. 2A).
All PGR treatments suppressed the root formation and induced callus formation at the base of explants (Fig. 2B), whereas on the PGR-free control medium, no callus formation occurred and normal roots were developed. The percentage of explants which showed callus formation ranged between $45.56 \%(18.16 \mu \mathrm{M} \mathrm{TDZ})$ and 100\% (all concentrations of BA and combinations of BA with auxins, as well as $4.65 \mu \mathrm{M} \mathrm{Kn}$ and $2.32 \mu \mathrm{M} \mathrm{Kn}+2.85 \mu \mathrm{M}$ IAA). The callus diameter ranged between $0.42 \mathrm{~cm}(9.08 \mu \mathrm{M}$ TDZ) and $1.06 \mathrm{~cm}(2.22 \mu \mathrm{M} \mathrm{BA}+2.85 \mu \mathrm{M}$ IAA) (Table 2).

PGR-supplemented media caused the formation of significant chlorosis and necrosis (Fig. 2C and D). WPM supplemented with $2.32 \mu \mathrm{M} \mathrm{Kn}+2.85 \mu \mathrm{M}$ IAA or $5.37 \mu \mathrm{M}$ NAA induced the highest percentage of chlorosis, and WPM supplemented with $4.65 \mu \mathrm{M} \mathrm{Kn}$ or $8.88 \mu \mathrm{M}$ BA caused the highest necrosis formation, respectively. In general, the presence of TDZ and combinations of cytokinin with auxin in the media induced a high percentage of chlorosis (Table 2).

Shoots grown on the PGR-free control medium proved to be the most suitable for in vitro propagation, since they showed, in general, a better development with respect to important criteria such as shoot length, length of internodes, and leaf size. In addition, no callus was formed at the base of the explants and root as well as shoot formation occurred simultaneously. Furthermore, neither necrosis nor chlorosis was detected (Fig. 1A).

The plantlets $(8-10 \mathrm{~cm}$ long with $10-14$ leaves and well-developed roots) (Fig. 3A) obtained from PGR-free control medium (WPM) were transferred to soil and were acclimatized over a period of 5 weeks (Fig. 3B and C). Completely acclimatized plants were transferred to field conditions at the end of 8 weeks (Fig. 3D).

Effect of PGRs on production of SGs. A comparative analysis regarding the stevioside and rebaudioside A production in leaves of shoots, grown in vitro on WPM supplemented with different PGRs was conducted. The results showed that the application of PGRs significantly affected the stevioside production under in vitro conditions. The highest stevioside content $\left(34.0 \mathrm{mg} \cdot \mathrm{g}^{-1}\right.$ DW) in the leaves was obtained with the PGR-free control medium and therefore turned out to be most suitable for the stevioside production (Table 3). Among the all PGRs applied, especially WPM supplemented with $2.27 \mu \mathrm{M}$ TDZ (20.60 mg. $\left.\mathrm{g}^{-1} \mathrm{DW}\right)$, $4.54 \mu \mathrm{M}$ TDZ $\left(26.40 \mathrm{mg} \cdot \mathrm{g}^{-1} \mathrm{DW}\right), 2.22 \mu \mathrm{M}$ $\mathrm{BA}+5.37 \mu \mathrm{M}$ NAA $\left(22.30 \mathrm{mg} \cdot \mathrm{g}^{-1} \mathrm{DW}\right)$, or $2.32 \mu \mathrm{M} \mathrm{Kn}+2.69 \mu \mathrm{M}$ NAA $\left(21.10 \mathrm{mg} \cdot \mathrm{g}^{-1}\right.$ DW) led to notable high contents of stevioside in the leaves (Table 3). Although TDZ had a negative effect on the shoot development, it accumulated considerably high stevioside content in the leaves in $2.27 \mu \mathrm{M}$ and $4.54 \mu \mathrm{M}$ concentrations used (Table 3). Only on the control medium, rebaudioside A (12.20 mg. $\mathrm{g}^{-1}$ DW) was detected.

The leaves of shoots grown on WPM supplemented with $2.27 \mu \mathrm{M}$ TDZ, $4.54 \mu \mathrm{M}$
TDZ, 2.22 $\mu \mathrm{M}$ BA + $2.69 \mu \mathrm{M}$ NAA, $2.22 \mu \mathrm{M}$ $\mathrm{BA}+5.37 \mu \mathrm{M}$ NAA, $2.32 \mu \mathrm{M} \mathrm{Kn}+5.71 \mu \mathrm{M} \mathrm{IAA}$, or $2.32 \mu \mathrm{M} \mathrm{Kn}+2.69 \mu \mathrm{M}$ NAA were identified because of their high stevioside content and were screened for qualitative confirmation of stevioside (molecular mass $=804.88 \mathrm{Da}$, molecular mass of $\left[\mathrm{M}+\mathrm{NH}_{4}\right]^{+}$adduct $=$ 822.88 Da, screened for $=821-823 \mathrm{Da})$, steviolbioside/rubusoside (molecular mass = $642.74 \mathrm{Da}$, molecular mass of $\left[\mathrm{M}+\mathrm{NH}_{4}\right]^{+}$ adduct $=660.74 \mathrm{Da}$, screened for $=659$ $661 \mathrm{Da})$, dulcoside A (molecular mass = $788.88 \mathrm{Da}$, molecular mass of $\left[\mathrm{M}+\mathrm{NH}_{4}\right]^{+}$ adduct $=806.88 \mathrm{Da}$, screened for $=805$ $807 \mathrm{Da}$ ), rebaudioside $\mathrm{A} / \mathrm{E}$ (molecular mass $=967.02 \mathrm{Da}$, molecular mass of $\left[\mathrm{M}+\mathrm{NH}_{4}\right]^{+}$adduct $=985.02 \mathrm{Da}$, screened for $=805-807 \mathrm{Da})$, rebaudioside $\mathrm{C}$ (molecular mass $=951.02 \mathrm{Da}$, molecular mass of $\left[\mathrm{M}+\mathrm{NH}_{4}\right]^{+}$adduct $=969.02 \mathrm{Da}$, screened for $=969-970 \mathrm{Da}$ ), rebaudioside $\mathrm{D}$ (molecular mass $=1129.16 \mathrm{Da}$, molecular mass of $\left[\mathrm{M}+\mathrm{NH}_{4}\right]^{+}$adduct $=1147.16 \mathrm{Da}$, screened for $=1147-1148 \mathrm{Da}$ ), and rebaudioside $\mathrm{F}$ (molecular mass $=936.99 \mathrm{Da}$, molecular mass of $\left[\mathrm{M}+\mathrm{NH}_{4}\right]^{+}$adduct $=954.99 \mathrm{Da}$, screened for $=954-956 \mathrm{Da})$. In all screened samples, steviolbioside/rubusoside and dulcoside A were detected as well as stevioside with various signal intensities.

\section{Discussion}

Effect of different explant types and PGRs on shoot proliferation and in vitro plant growth. Shoot tips and nodal segments were used as explant sources. Because genetically stable and true-to-type plantlets can be obtained by using shoot tips and axillary buds in micropropagation (Faisal et al., 2007). Nodal explants are suitable for a large-scale production and multiple shoots can easily be obtained in vitro from this explant type.

Cytokinins are generally added alone or along with auxins to the nutrient medium to promote multiple shoot formation. We found that BA-containing media were found to be more effective than $\mathrm{Kn}$ - and TDZ-containing media with regard to the shoot multiplication. A similar result was also observed in other micropropagation studies of $S$. rebaudiana (Sivaram and Mukundan, 2003; Sridhar and Aswath, 2014; Thiyagarajan and Venkatachalam, 2012). On the contrary, Lata et al. (2013) observed that TDZ was more effective for shoot proliferation of $S$. rebaudiana than BA and $\mathrm{Kn}$. BA concentrations higher than 4.44 $\mu \mathrm{M}$ resulted in the growth of plantlets with a bushy appearance, very thin shoots and small leaves and therefore they were not suitable for in vitro propagation (Fig. 1B). Ibrahim et al. (2008) found similar results in $S$. rebaudiana. They obtained the highest number of shoots on Murashige and Skoog (MS) basal medium supplemented with $2 \mathrm{mg} \cdot \mathrm{L}^{-1} \mathrm{BA}$, but the shoots were also very thin and unsuitable for propagation. We found that TDZ suppressed significantly the shoot formation and the growth and caused in all concentrations alterations of the shoot morphology. The regenerated shoots were 

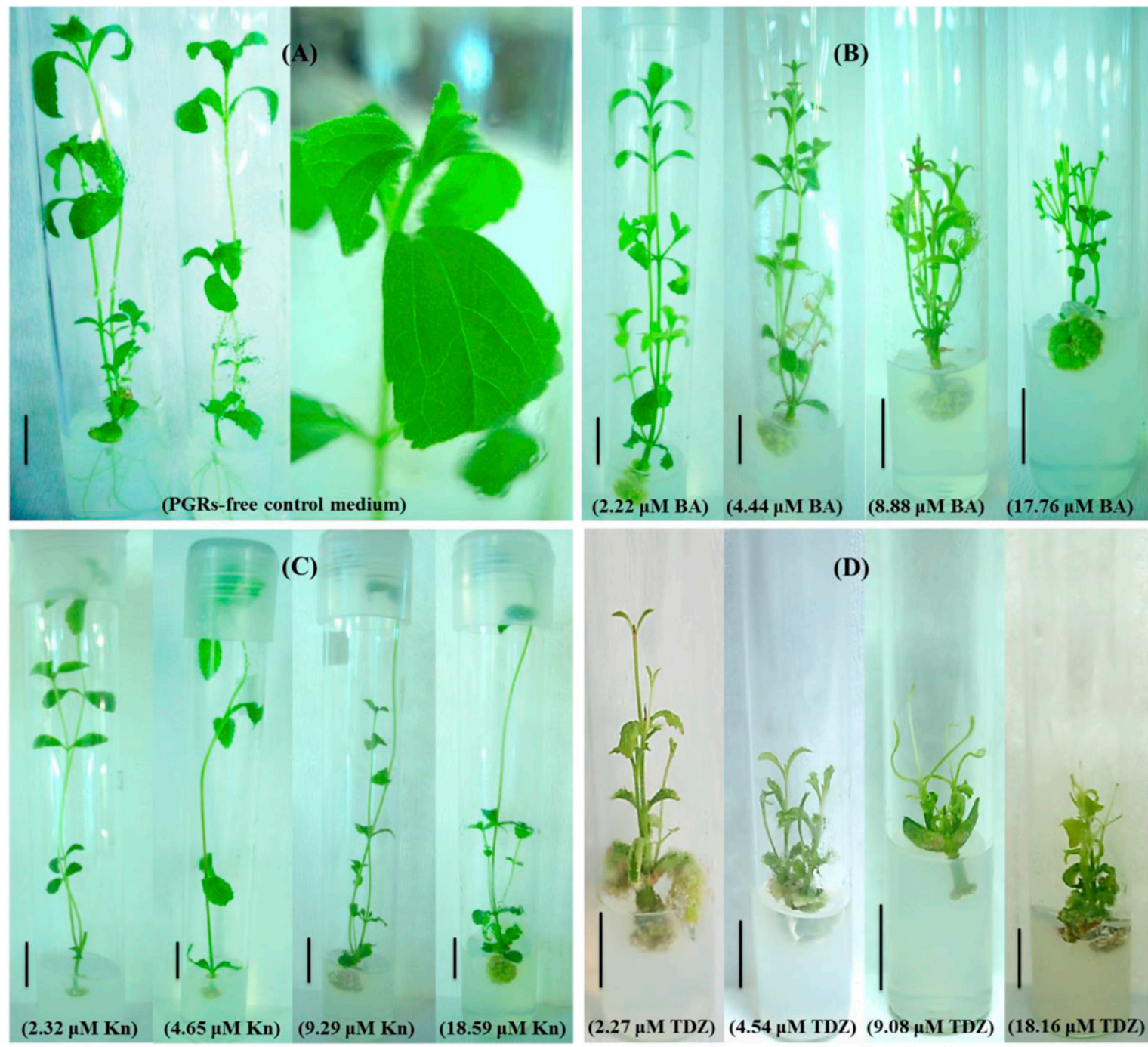

(D)
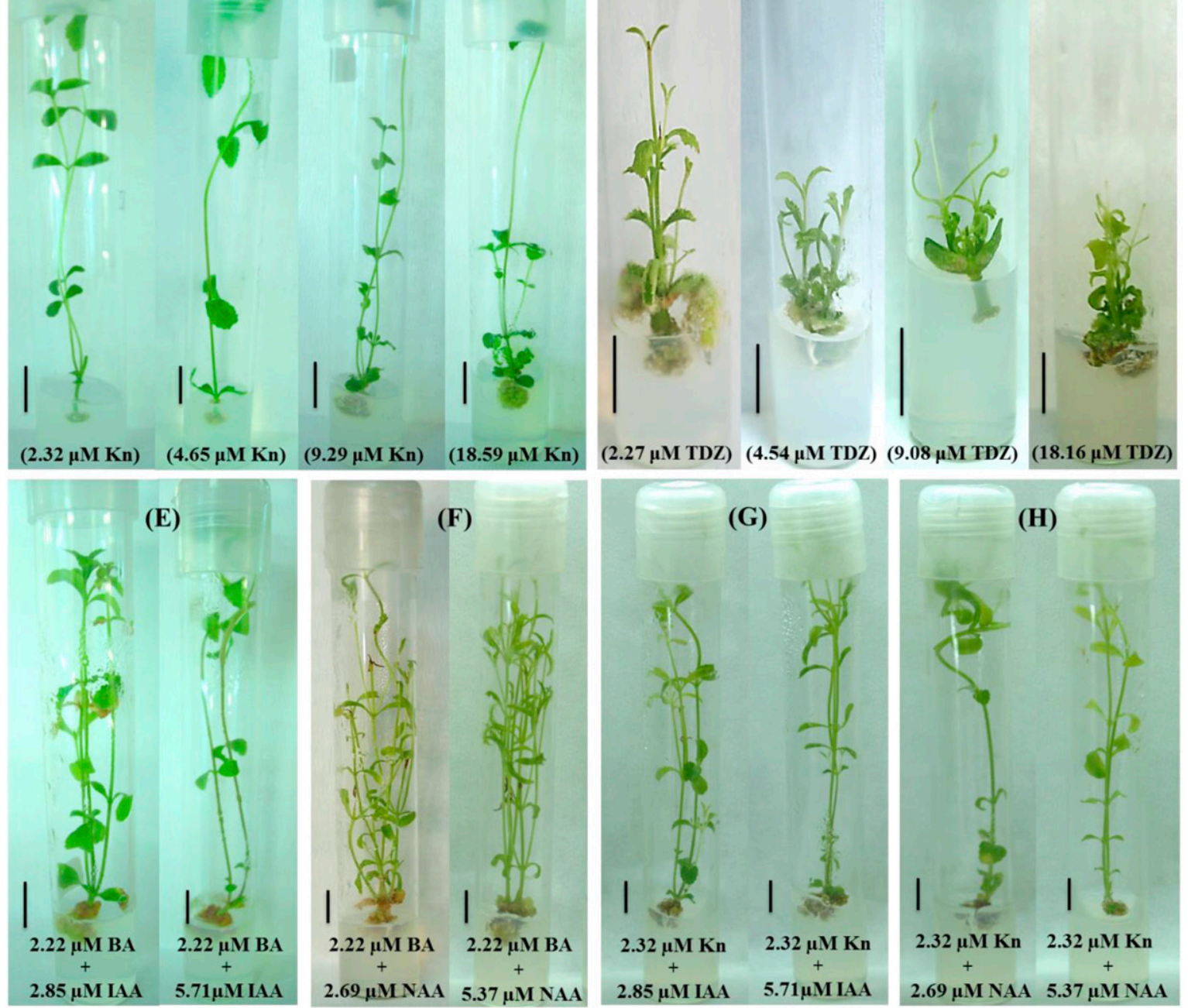

Fig. 1. The morphology of Stevia rebaudiana shoots (4 weeks old) cultivated on PGR-free WPM medium (A) and the effect of cytokinins and auxin + cytokinin combinations on the morphology of S. rebaudiana shoots (4 weeks old) cultivated on WPM medium supplemented with: BA $(2.22,4.44,8.88$, and 17.76 $\mu$ M) (B); $\mathrm{Kn}(2.32,4.65,9.29$, and $18.59 \mu \mathrm{M})(\mathbf{C})$; TDZ $(2.27,4.54,9.08$, and $18.16 \mu \mathrm{M})(\mathbf{D})$; BA + IAA combinations $(2.22 \mu \mathrm{M} \mathrm{BA}+2.85 \mu \mathrm{M} \mathrm{IAA}, 2.22 \mu \mathrm{M}$ BA + $5.71 \mu \mathrm{M}$ IAA) (E); BA + NAA combinations $(2.22 \mu \mathrm{M}$ BA + $2.69 \mu \mathrm{M}$ NAA, $2.22 \mu \mathrm{M}$ BA + 5.37 $\mu \mathrm{M}$ NAA) (F); Kn + IAA combinations $(2.32 \mu \mathrm{M}$ Kn + $2.85 \mu \mathrm{M}$ IAA, $2.32 \mu \mathrm{M} \mathrm{Kn}+5.71 \mu \mathrm{M} \mathrm{IAA})(\mathbf{G}) ; \mathrm{Kn}+\mathrm{NAA}$ combinations $(2.32 \mu \mathrm{M} \mathrm{Kn}+2.69 \mu \mathrm{M}$ NAA, $2.32 \mu \mathrm{m} \mathrm{Kn}+5.37 \mu \mathrm{M}$ NAA) $(\mathbf{H})$. Scale bar $=1 \mathrm{~cm}$. PGR $=$ plant growth regulator; WPM = woody plant medium; BA = 6-benzyladenine; TDZ = thidiazuron; IAA = indoleacetic acid; NAA = naphthaleneacetic acid; Kn = kinetin.

short and thin with smaller and abnormal leaves (Fig. 1D). Kataeva et al. (1991) reported that the addition of PGRs to the medium might alter the hormone content and/ or balance in explants, promoting abnormal plant growth.

On WPM medium containing $2.22 \mu \mathrm{M} \mathrm{BA}+$ $2.69 \mu \mathrm{M}$ NAA, the number of shoots per shoot tip explant was 8.35-fold higher compared with the number obtained on the PGR-free control medium. The positive effect of BA + NAA combinations on shoot proliferation of 

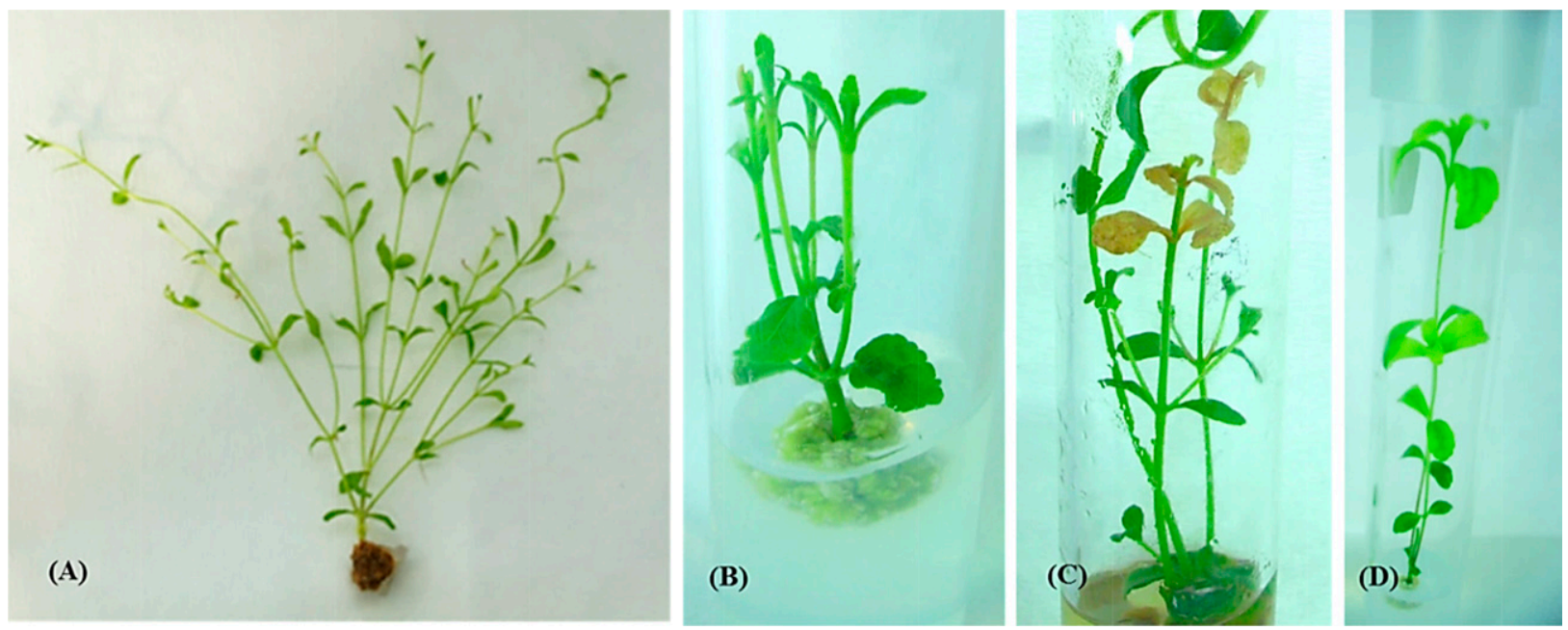

Fig. 2. Examples of in vitro shoot regeneration of Stevia rebaudiana: plantlet developed on plant growth regulator (PGR)-containing media (A); callus formation at the basal end of in vitro shoot $(\mathbf{B})$; necrotic shoot $(\mathbf{C})$; chlorotic shoot $(\mathbf{D})$. Scale bar $=1 \mathrm{~cm}$.

Table 2. Effects of different types and concentrations of PGRs on the in vitro shoot growth of Stevia rebaudiana.

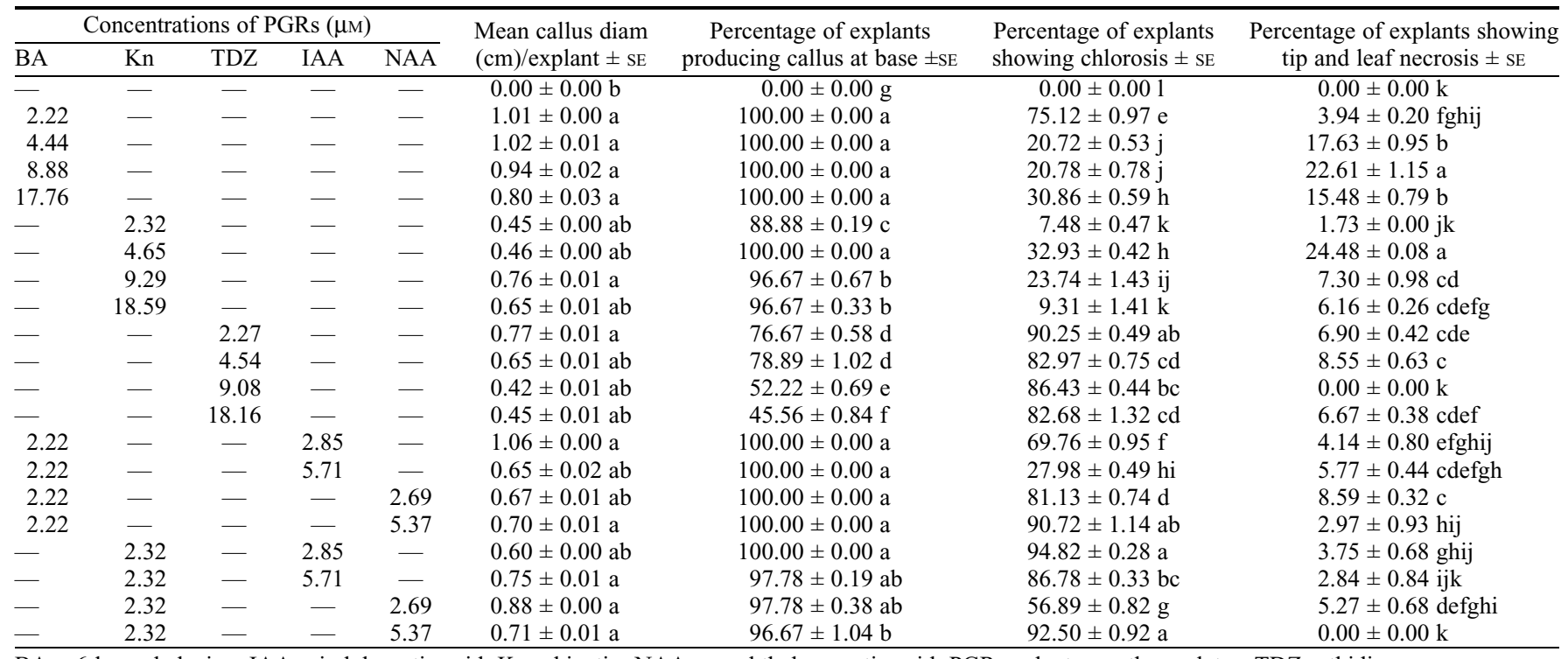

$\mathrm{BA}=$ 6-benzyladenine; IAA = indoleacetic acid; $\mathrm{Kn}=$ kinetin; $\mathrm{NAA}=$ naphthaleneacetic acid; PGR = plant growth regulator; $\mathrm{TDZ}=$ thidiazuron.

Values represent mean \pm SE of three replications, with 15 explants per replicate. Values (mean $\pm \mathrm{SE}$ ) sharing the same letter in the same column is not significantly different at $P \leq 0.01$, according to least significant difference test. Data were recorded after 4 weeks of culture.

S. rebaudiana is consistent with other studies (Bondarev et al., 2003; Giridhar et al., 2010; Soliman et al., 2014). Bondarev et al. (2003) achieved a 1.5-fold higher shoot number on MS medium supplemented with $0.1 \mathrm{mg} \cdot \mathrm{L}^{-1} \mathrm{BA}$ and NAA compared with the number obtained on the PGR-free control medium.

Up to now, there are a lot of reports regarding in vitro propagation of Stevia using stem tips with a few leaf primordia, nodal or leaf explants (Aman et al., 2013; Sivaram and Mukundan, 2003; Tamura et al., 1984; Thiyagarajan and Venkatachalam, 2012; Yang et al., 1981). The highest number of shoots per explant obtained from micropropagation studies of $S$. rebaudiana varies considerably such as 40 shoots/explant (Tamura et al., 1984), 11.2 shoots/explant (Sivaram and Mukundan, 2003), 23.4 shoots/ explant (Hwang, 2006), 8.75 shoots/explant (Ahmed et al., 2007), 83.2 shoots/explant (Sairkar et al., 2009), 28 shoots/explant (Giridhar et al., 2010), 40.54 shoots/explant (Satpathy and Das, 2010), 15.69 shoots/explant (Thiyagarajan and Venkatachalam, 2012), 60 shoots/explant (Lata et al., 2013). In the present study, the highest number of shoots per explant was 10.02 . This variety among the results may be due to used explant, basal medium and PGRs and the endogenous level of PGRs in used explants.

In previous publications, it is stated that for rooting of in vitro regenerated shoots of $S$. rebaudiana an additional rooting medium is necessary. For this purpose, different media were used: Linsmaier and Skoog medium with $0.1 \mathrm{mg} \cdot \mathrm{L}^{-1}$ NAA (Tamura et al., 1984), half-strength MS medium with $4.90 \mu \mathrm{M}$ indole3-butyric acid (IBA) (Sivaram and Mukundan,
2003), MS medium with $0.1 \mathrm{mg} \cdot \mathrm{L}^{-1}$ IAA (Ahmed et al., 2007), MS medium with $2.0 \mathrm{mg} \cdot \mathrm{L}^{-1}$ IBA (Hwang, 2006). We were able to develop a one-step in vitro propagation protocol. On the PGR-free control medium (WPM) the development of shoots and roots occurred simultaneously and healthy and well developed plantlets were obtained. The plantlets showed no callus formation at the base of the explants and also no chlorosis and necrosis. At the same time, a good rooting was achieved (Fig. 3A). This result is in accordance with the results reported by Ibrahim et al. (2008). Regeneration in the absence of PGRs could both reduce the costs and make the process more efficient as the risk of somaclonal variations is reduced (Ibrahim et al., 2008).

The occurrence of necrosis and chlorosis to a considerable extent (Fig. 2C and D) and 

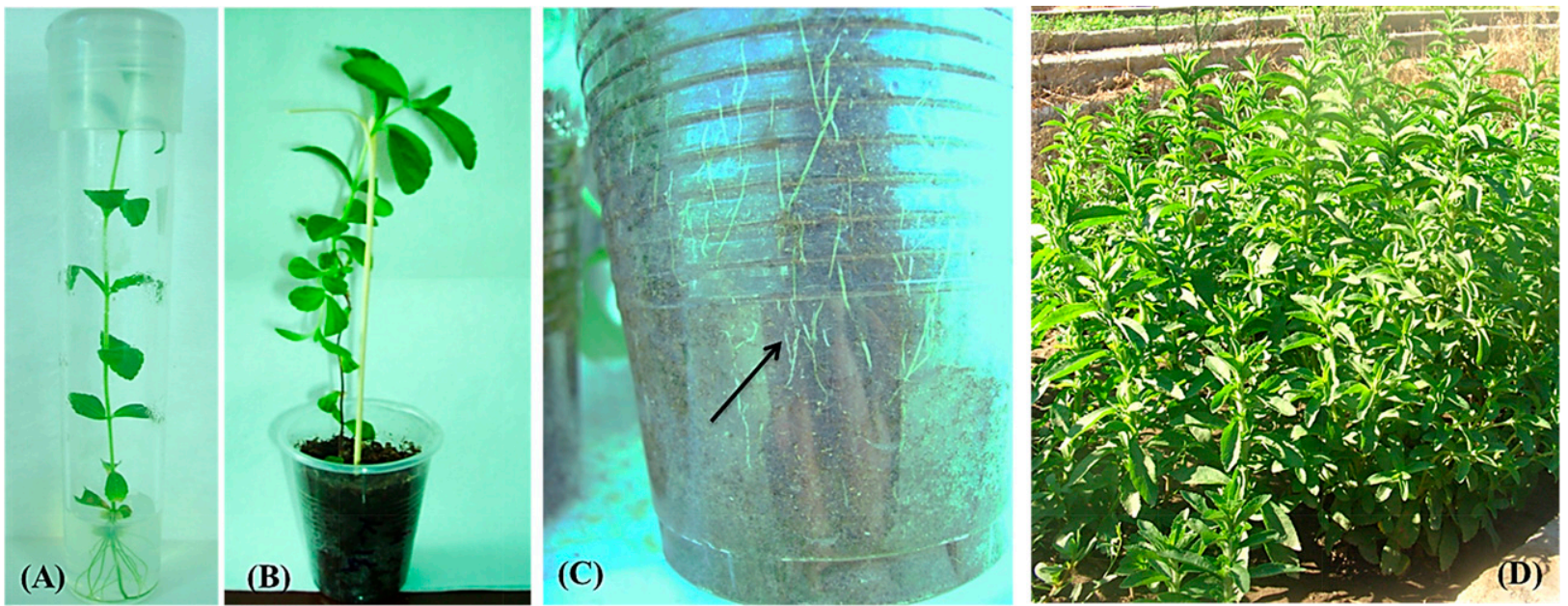

Fig. 3. Acclimatization of Stevia rebaudiana plantlets: rooted plantlets on woody plant medium (WPM) (A); acclimatized plantlets (B); root development in 5-cm pots containing a 1:3 peat to loam mixture $(\mathbf{C})$; hardened plants in the field (D).

Table 3. Effects of different types and concentrations of PGRs on the stevioside and rebaudioside A content (mg.g ${ }^{-1}$ dry weight) in leaves of in vitro grown Stevia rebaudiana.

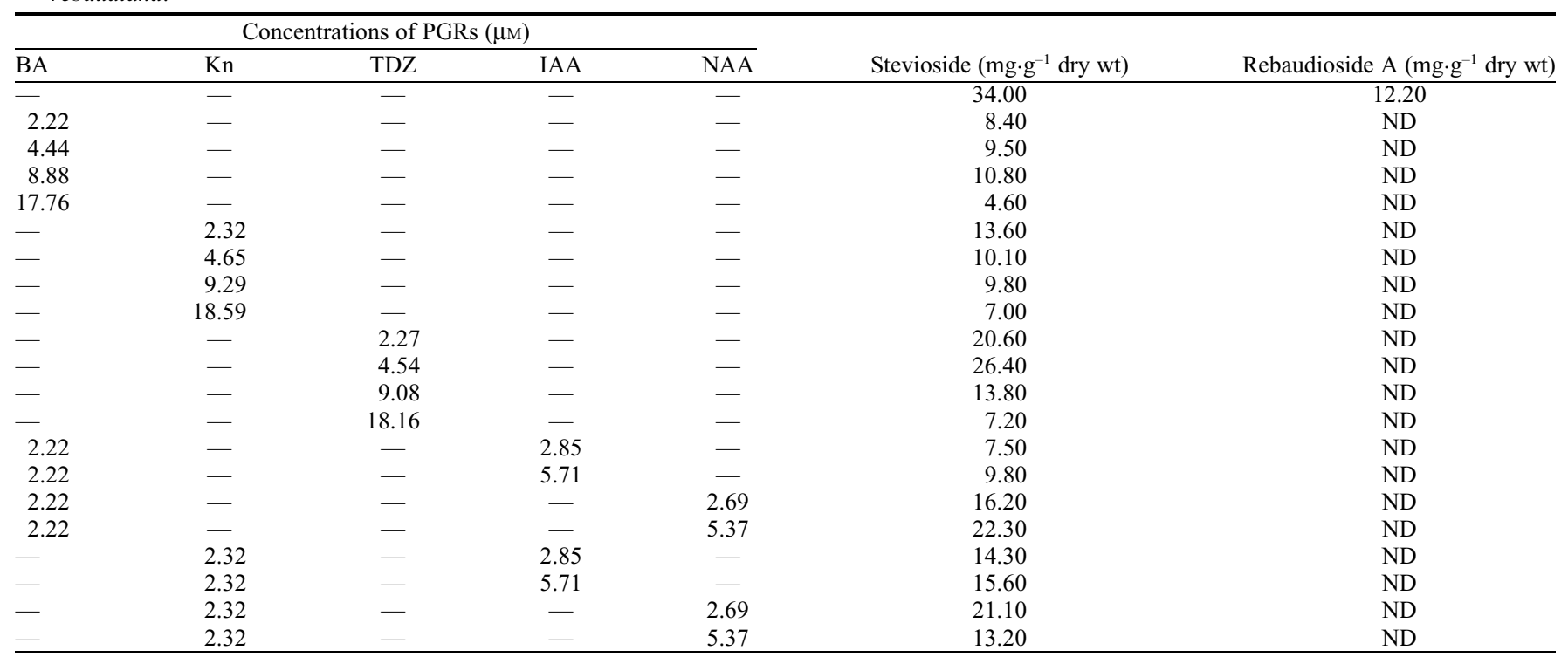

$\mathrm{BA}=6$-benzyladenine; IAA = indoleacetic acid; $\mathrm{Kn}=$ kinetin; $\mathrm{NAA}=$ naphthaleneacetic acid; $\mathrm{ND}=$ not determined; PGR = plant growth regulator; TDZ = thidiazuron.

the formation of callus instead of roots (Fig. 2B) were significant adverse effects, when PGRs containing media were used. Cassells and Curry (2001) associated the occurrence of necrosis with basal callus formation and reported that callus formation at the basal part of the explants caused the loss of the apical dominance of the shoots. The formation of chlorosis and necrosis in the shoots might be explained in a similar manner. The lack of root formation, which is one of the most effective factors in endogenous cytokinin biosynthesis, might lower the internal cytokinin levels, ceasing cell division and causing necrosis in the apical meristem (Kataeva et al., 1991). In the present study, the explants formed shoots as well as callus tissue at the basal part of the explants, therefore the minerals and PGRs in the medium were needed for the growth of two different tissue formations and thus could have led to an imbalance in their distribution. Furthermore, besides an imbalanced use of minerals and PGRs for the callus growth, the development of callus tissue, instead of roots, has probably also obstructed the transport of minerals to the shoots, which on the other hand, most likely induced the formation of chlorosis and necrosis. Tamura et al. (1984) reported that callus formation at the basal parts of shoots was prevented by culturing the stem tips of shoots in medium containing only cytokinins, whereas on media containing both Kn and NAA, callus formation was promoted. The aforementioned result does not support our findings. As the usage of cytokinins individually did not prevent callus formation in the basal part of in vitro shoots. The other result agrees with the results of the present study. Since Kn + NAA combination caused callus formation in the basal part of in vitro shoots.

Effect of PGRs on production of SGs. Internal factors such as PGRs were reported to affect the secondary metabolite production along with external factors such as temperature, light, $\mathrm{pH}$ and salt concentration. Consequently, secondary metabolite production might be promoted by the addition of suitable PGRs to the medium, modification of the composition of the growth medium and by alteration of the physical conditions of the culture. Therefore, we investigated the effect of various cytokinins and various cytokininauxin combinations on the secondary metabolite production of $S$. rebaudiana. Previous investigations regarding the content of secondary metabolites of Stevia, focused on the determination of SGs in the donor plant and the in vitro plant material, regenerated from 
the donor plants. Bondarev et al. (2001) found in different plant material of a $S$. rebaudiana clone, following stevioside and rebaudioside A contents ( $\mathrm{mg} \cdot \mathrm{g}^{-1}$ dry matter): 24.9 and $12.0 \mathrm{mg} \cdot \mathrm{g}^{-1}$ in leaves of intact plants, 3.4 and $1.0 \mathrm{mg} \cdot \mathrm{g}^{-1}$ in leaves of in vitro plants, $0.015 \mathrm{mg} \cdot \mathrm{g}^{-1}$ and a trace amount in material of a suspension culture, 0.060 and $0.023 \mathrm{mg} \cdot \mathrm{g}^{-1}$ in morphogenic callus and 0.387 and $0.112 \mathrm{mg} \cdot \mathrm{g}^{-1}$ in shoots, regenerated in vitro from callus. They also established a callus culture on MS medium supplemented with $1 \mathrm{mg} \cdot \mathrm{L}^{-1} \mathrm{NAA}$ and $0.5 \mathrm{mg} \cdot \mathrm{L}^{-1}$ 6-benzyl aminopurine in continuous darkness; however, they found no stevioside and rebaudioside A in this culture. SGs are thought to be produced in the chloroplasts and therefore it comes as no surprise that callus cultures grown in the dark, by Bondarev et al., were found not to contain SGs. We found in leaves of shoots grown in vitro on WPM (in light), containing the same PGRs in the same concentration as indicated by Bondarev et al. (2001) a stevioside content of 22.3 $\mathrm{mg} \cdot \mathrm{g}^{-1}$ DW. Ladygin et al. (2008) found a positive correlation between the development and activity of the photosynthetic apparatus in Stevia leaves and the biosynthesis of diterpenoid SGs. The initiation of the biosynthesis of SGs is reported to take place in chloroplasts (Brandle and Telmer, 2007; Ladygin et al., 2008). Heterotrophic callus cells grown in the dark held almost no pigments and they did not synthesize SGs (Ladygin et al., 2008). Yamazaki and Flores (1991) suggested that SGs are synthesized in the leaves not in the roots of $S$. rebaudiana. Reis et al. (2011) established successfully an adventitious root culture of $S$. rebaudiana in a roller bottle system, but no stevioside and other major SGs were synthesized in this culture. Aman et al. (2013) investigated the effect of some PGRs and different concentrations of agar on the dulcoside-A, stevioside and rebaudioside-A production in in vitro shoots of $S$. rebaudiana. They reported that the highest content of dulcoside-A (71.8 $\mu \mathrm{g} \mathrm{g}^{-1} \quad$ DW), stevioside $\left(82.48 \mu \mathrm{g} \cdot \mathrm{g}^{-1} \mathrm{DW}\right)$ and rebaudioside A (12.35 $\left.\mu \mathrm{g} \cdot \mathrm{g}^{-1} \mathrm{DW}\right)$ were observed in shoots grown on medium, containing a combination of $\mathrm{BA}$ and $\mathrm{Kn}\left(3.0 \mathrm{mg} \cdot \mathrm{L}^{-1}\right)$ with $3.5 \mathrm{~g} \cdot \mathrm{L}^{-1}$ agar, a combination of BA and $\mathrm{Kn}\left(3.0 \mathrm{mg} \cdot \mathrm{L}^{-1}\right)$ with 7.0 $\mathrm{g} \cdot \mathrm{L}^{-1}$ agar and on medium containing only $\mathrm{BA}$ (1.0 mg. $\left.\mathrm{L}^{-1}\right)$ with $7.0 \mathrm{~g} \cdot \mathrm{L}^{-1}$ agar, respectively.

Even though the addition of BA to the culture medium stimulated the multiple shoot production, inhibited the biosynthesis of stevioside. Similar results regarding the effect of $\mathrm{BA}$ on the SGs formation were reported (Bondarev et al., 2003; Sivaram and Mukundan, 2003). In the present study, Kn limited both multiple shoot induction and secondary metabolite production in the leaves of $S$. rebaudiana. The addition of all PGRs, PGR combinations and PGR concentrations tested, resulted compared with the content achieved on the PGR-free control medium, in a considerable lower stevioside content in the leaves. The conversion of stevioside into rebaudioside A is the terminal step in the metabolic pathway of the SGs (Brandle and Telmer, 2007).
The addition of $\mathrm{BA}$ and $\mathrm{Kn}$ to the culture media had a negative effect on the stevioside formation and the conversion of stevioside into rebaudioside A was completely inhibited. Since BA promotes the multiple shoot formation and $\mathrm{Kn}$ the growth, it can be assumed that in response to the addition of these PGRs, an active primary metabolism is prioritized by the plant and consequently the formation of secondary metabolites is reduced.

Among the all PGRs applied, the highest stevioside content $\left(26.40 \mathrm{mg} \cdot \mathrm{g}^{-1} \mathrm{DW}\right)$ were detected in shoots grown on WPM supplemented with $4.54 \mu \mathrm{M}$ TDZ. There has been no published data regarding the effect of TDZ on the stevioside A content in $S$. rebaudiana.

Callus tissue, as it was formed at the base of shoots, grown on TDZ-containing media, can obstruct the vascular connection between shoot and medium and therefore result in a reduction or cessation of passageways for minerals and PGRs toward the shoots. With the time this leads to a decrease of the internal hormone level, which in turn inhibits the apical cell division and limits the plant growth. As a result chlorosis followed by necrosis might occur, as it was observed. At this stage, the plant growth stops due to the stress. Therefore, the remaining resources might be supplied to the secondary metabolism and thus lead to an increased formation of secondary metabolites. This might explain the high contents of rebaudioside A, as they were found.

In the first step of SGs pathway, steviol convert into steviolmonoside and in the second step, steviolmonoside convert into steviolbioside or rubusoside. After the glycosylation of steviolbioside, stevioside, and rebaudioside $\mathrm{A}$, stevioside, rebaudioside $\mathrm{A}$, and rebaudioside D occur, respectively (Prakash et al., 2014). It is also reported that there is a wide range of variation in the four main glycosides and a positive correlation between dulcoside A and stevioside and a negative correlation between stevioside and rebaudioside A. These correlations result from the biosynthetic relationships between the individual glycosides (Brandle et al., 1998). According to Brandle and Telmer (2007), rubusoside synthesis is inhibited with the preferred synthesis of steviolbioside. In the present study, steviolbioside was detected qualitatively in the leaves of shoots grown on selected media (WPM supplemented with $2.27 \mu \mathrm{M}$ TDZ, $4.54 \mu \mathrm{M}$ TDZ, $2.22 \mu \mathrm{M}$ BA $+2.69 \mu \mathrm{M}$ NAA, $2.22 \mu \mathrm{M}$ BA $+5.37 \mu \mathrm{M}$ NAA, $2.32 \mu \mathrm{M} \mathrm{Kn}+$ $5.71 \mu \mathrm{M}$ IAA or $2.32 \mu \mathrm{M} \mathrm{Kn}+2.69 \mu \mathrm{M}$ NAA) as well as rubusoside and no rebaudioside A was determined. This may be because the SGs pathway was directed rubusoside synthesis and thus rebaudioside A synthesis was slowed down. In addition to stevioside, steviolbioside, and rubusoside, dulcoside A were also detected. The determination of dulcoside A in the selected media can be explained by the presence of stevioside.

\section{Conclusion}

A simple and low-cost in vitro propagation procedure was developed for $S$. rebaudiana.
We were able to develop a one-step in vitro propagation protocol. On the PGR-free WPM, shoots and roots were formed simultaneously and well-developed plantlets were obtained without the use of an additional rooting medium or the use of PGRs. Furthermore, the highest stevioside content was determined in leaves of plants regenerated on this medium. All plantlets obtained from PGR-free control medium were successfully acclimatized in a glasshouse and then plants were transferred to the field. This in vitro propagation procedure has been adapted by a commercial plant tissue culture laboratory.

\section{Literature Cited}

Acikgoz, N., E. Ilker, and E. Gokcol. 2004. Analysis methods of biological researches. Seed Technology Center, Publication 2, Izmir, Turkey.

Ahmed, M.B., M. Salahin, R. Karim, M.A. Razvy, M.M. Hannan, R. Sultana, M. Hossain, and R. Islam. 2007. An efficient method for in vitro clonal propagation of a newly introduced sweetener plant (Stevia rebaudiana Bertoni) in Bangladesh. American-Eurasian J. Sci. Res. 2:121-125

Aman, N., F. Hadi, S.A. Khalil, R. Zamir, and N. Ahmad. 2013. Efficient regeneration for enhanced steviol glycosides production in Stevia rebaudiana (Bertoni). C. R. Biol. 336:486-492.

Bondarev, N., O. Reshetnyak, and A. Nosov. 2001. Peculiarities of diterpenoid steviol glycoside production in in vitro cultures of Stevia rebaudiana Bertoni. Plant Sci. 161:155-163.

Bondarev, N., O. Reshetnyak, and A. Nosov. 2003. Effects of nutrient medium composition on development of Stevia rebaudiana shoots cultivated in the roller bioreactor and their production of steviol glycosides. Plant Sci. 165:845-850.

Brandle, J.E., A.N. Starrat, and M. Gijen. 1998. Stevia rebaudiana: Its agricultural, biological, and chemical properties. Can. J. Plant Sci. 78:527-536.

Brandle, J.E. and P.G. Telmer. 2007. Steviol glycoside biosynthesis. Phytochemistry 68:18551863.

Cassells, A.C. and R.F. Curry. 2001. Oxidative stress and physiological, epigenetic and genetic variability in plant tissue culture: Implications for micropropagators and genetic engineers. Plant Cell Tissue Organ Cult. 64:145-157.

Ceunen, S. and J.M.C. Geuns. 2013. Influence of photoperiodism on the spatio-temporal accumulation of steviol glycosides in Stevia rebaudiana (Bertoni). Plant Sci. 198:72-82.

Faisal, M., N. Ahmad, and M. Anis. 2007. An efficient micropropagation system for Tylophora indica: An endangered, medicinally important plant. Plant Biotechnol. Rep. 1:155-161.

Gantait, S., A. Das, and N. Mandal. 2015. Stevia: A comprehensive review on ethnopharmacological properties and in vitro regeneration. Sugar Tech 17(2):95-106.

Giridhar, P., K.S. Sowmya, A. Ramakrishna, and G.A. Ravishankar. 2010. Rapid clonal propagation and stevioside profiles of Stevia rebaudiana Bertoni. Intl. J. Plant Dev. Biol. 4(1):47-52.

Gupta, P., S. Sharma, and S. Saxena. 2014. Effect of salts $\left(\mathrm{NaCl}\right.$ and $\left.\mathrm{Na}_{2} \mathrm{CO}_{3}\right)$ on callus and suspension culture of Stevia rebaudiana for steviol glycoside production. Appl. Biochem. Biotechnol. 172(6):2894-2906.

Gupta, P., S. Sharma, and S. Saxena. 2015. Biomass yield and steviol glycoside production in callus and suspension culture of Stevia rebaudiana treated with proline and polyethylene glycol. Appl. Biochem. Biotechnol. 176(3):863-874. 
Hwang, S.J. 2006. Rapid in vitro propagation and enhanced stevioside accumulation in Stevia rebaudiana Bert. J. Plant Biol. 49(4):267-270.

Ibrahim, I.A., M.I. Nasr, B.R. Mohammed, and M.M. El-Zefzafi. 2008. Plant growth regulators affecting in vitro cultivation of Stevia rebaudiana. Sugar Tech 10:254-259.

Kataeva, N.V., I.G. Alexandrova, R.G. Butenko, and E.V. Dragavtceva. 1991. Effect of applied and internal hormones on vitrification and apical necrosis of different plants cultured in vitro. Plant Cell Tissue Organ Cult. 27:149-154.

Keller, B.O., J. Sui, A.B. Young, and R.M. Whittal. 2008. Interferences and contaminants encountered in modern mass spectrometry. Anal. Chim. Acta 627(1):71-81.

Kinghorn, A.D. 2002. Overview, p. 10-17. In: A.D. Kinghorn (ed.). Stevia: The genus Stevia. Taylor and Francis, London, UK.

Ladygin, V.G., N.I. Bondarev, G.A. Semenova, A.A. Smolov, O.V. Reshetnyak, and A.M. Nosov. 2008. Chloroplast ultrastructure, photosynthetic apparatus activities and production of steviol glycosides in Stevia rebaudiana in vivo and in vitro. Biol. Plant. 52:9-16.

Lata, H., S. Chandra, Y.H. Wang, V. Raman, and I.A. Khan. 2013. TDZ-induced high frequency plant regeneration through direct shoot organogenesis in Stevia rebaudiana bertoni: An important medicinal plant and a natural sweetener. Amer. J. Plant Sci. 4:117-128.

Lemus-Mondaca, R., A. Vega-Gálvez, L. ZuraBravo, and K. Ah-Hen. 2012. Stevia rebaudiana Bertoni, source of a high-potency natural sweetener: A comprehensive review on the biochemical, nutritional and functional aspects. Food Chem. 132:1121-1132.
Lloyd, G. and B. McCown. 1980. Commerciallyfeasible micropropagation of mountain laurel, Kalmia latifolia, by use of shoot tip culture. Intl. Plant Prop. Soc. 30:421-427.

Mathur, S. and G.S. Shekhawat. 2013. Establishment and characterization of Stevia rebaudiana (Bertoni) cell suspension culture: An in vitro approach for production of stevioside. Acta Physiol. Plant. 35:931-939.

Pandey, H., P. Pandey, S.S. Pandey, S. Singh, and S. Banerjee. 2016. Meeting the challenge of stevioside production in the hairy roots of Stevia rebaudiana by probing the underlying process. Plant Cell Tissue Organ Cult. 126 (3):511-521.

Prakash, I., C. Bunders, K.P. Devkota, R.D. Charan, C. Ramirez, C. Priedemann, and A. Markosyan. 2014. Isolation and structure elucidation of rebaudioside D2 from bioconversion reaction of rebaudioside A to rebaudioside D. Nat. Prod. Commun. 9(8):1135-1138.

Reis, R.V., A.P.P.L. Borges, T.P.C. Chierrito, E.R. de Souto, L.M. de Souza, M. Iacomini, A.J.B. de Oliveira, and R.A.C. Gonçalves. 2011. Establishment of adventitious root culture of Stevia rebaudiana Bertoni in a roller bottle system. Plant Cell Tissue Organ Cult. 106:329335.

Sairkar, P., M.K. Chandravanshi, N.P. Shukla, and N.N. Mehrotra. 2009. Mass production of an economically important medicinal plant Stevia rebaudiana using in vitro propagation techniques. J. Med. Plants Res. 3(4):266-270.

Satpathy, S. and M. Das. 2010. In vitro shoot multiplication in Stevia rebaudiana Bert., a medicinally important plant. Gen. Appl. Plant Physiol. 36(3-4):167-175.
Sivaram, L. and U. Mukundan. 2003. In vitro culture studies on Stevia rebaudiana. In Vitro Cell. Dev. Biol. Plant 39:520-523.

Soejarto, D.D. 2002. Ethnobotany of Stevia and Stevia rebaudiana, p. 40-67. In: A.D. Kinghorn (ed.). Stevia: The genus Stevia. Taylor and Francis, London, UK.

Soliman, H.I.A., E.M.R. Metwali, and O.A.H. Almaghrabi. 2014. Micropropagation of Stevia rebaudiana Betroni and assessment of genetic stability of in vitro regenerated plants using inter simple sequence repeat (ISSR) marker. Plant Biotechnol. 31:249256.

Sridhar, T.M. and C.R. Aswath. 2014. Influence of additives on enhanced in vitro shoot multiplication of Stevia rebaudiana (Bert.): An important anti diabetic medicinal plant. A. J. Plant Sci. 5:192-199.

Tamura, Y., S. Nakamura, H. Fukui, and M. Tabata. 1984. Clonal propagation of Stevia rebaudiana Bertoni by stem-tip culture. Plant Cell Rep. 3:183-185.

Thiyagarajan, M. and P. Venkatachalam. 2012. Large scale in vitro propagation of Stevia rebaudiana (Bert.) for commercial application: Pharmaceutically important and antidiabetic medicinal herb. Ind. Crops Prod. 37:111-117.

Yamazaki, T. and H.E. Flores. 1991. Examination of steviol glucosides production by hairy root and shoot cultures of Stevia rebaudiana. J. Nat. Prod. 54:986-992.

Yang, Y.W., Y.I. Hsing, and W.C. Chang. 1981. Clonal propagation of Stevia rebaudiana Bertoni through axillary shoot proliferation in vitro. Bot. Bull. Acad. Sin. 22:57-62. 